\title{
Induction of apoptosis by thiosulfinates in primary human prostate cancer cells
}

\author{
SO-YEON KIM ${ }^{1}$, KYOUNG-WUK PARK ${ }^{1}$, JAE-YONG KIM ${ }^{3}$, MI-YAE SHON ${ }^{4}$, SUNG-TAE YEE ${ }^{2}$, \\ KEE-HONG KIM ${ }^{5}$, JOHNG S. RHIM ${ }^{5}$, KOJI YAMADA ${ }^{6}$ and KWON-IL SEO ${ }^{1}$ \\ Departments of ${ }^{1}$ Food and Nutrition, and ${ }^{2}$ Biology, Sunchon National University, Suncheon; \\ ${ }^{3}$ Department of Food Science and Technology, Kyungpook National University, Daegu; \\ ${ }^{4}$ Department of Food and Nutrition,Gyeongsang National University, Jinju, Republic of Korea; \\ ${ }^{5}$ Center for Prostate Disease Research, Department of Surgery, Uniformed Services University of Health Sciences, \\ Bethesda, MD, USA; ${ }^{6}$ Department of Bioscience and Biotechnology, Kyushu University, Fukuoka, Japan
}

Received October 30, 2007; Accepted December 18, 2007

\begin{abstract}
Thiosulfinates, a substance of Allium tuberosum L., is a known folk medicine that has been extensively used in diet to treat diseases. In the present study, we have evaluated the effect of thiosulfinates from Allium tumberosum L. on proliferation of metastasis (DU145) and primary malignant tumor (RC-58T/h/SA\#4)-derived human prostate cancer cells. Thiosulfinates decrease viable cell numbers in a dose- and time-dependent manner and induce apoptosis. The apoptosis induced by thiosulfinates is associated with the activation of initiator caspase-8, and -9 , and the effector caspase- 3 . Thiosulfinates stimulated Bid cleavage, indicating that the apoptotic action of caspase-8-mediated Bid cleavage leads to the activation of caspase-9. Thiosulfinates decreased the expression of the anti-apoptotic protein $\mathrm{Bcl}-2$, and increased the expression of the pro-apoptotic protein Bax. Thiosulfinates also increased the expression of AIF, a caspaseindependent mitochondrial apoptosis factor, in RC-58T/h/\#4 cells and induced DNA fragmentation and chromatin condensation. These results indicate that thiosulfinates from Allium tuberosum $L$. inhibit cell proliferation by inducing apoptosis in RC-58T/h/\#4 cells which may be mediated via both caspase-dependent and caspase-independent pathways.
\end{abstract}

Correspondence to: Dr Kwon-Il Seo, Department of Food and Nutrition, Sunchon National University, 315 Maegok, Suncheon, Jeonnam 540-742, Republic of Korea

E-mail: seoki@sunchon.ac.kr

Abbreviations: DMEM, Dulbecco's modified Eagle's medium; FBS, fetal bovine serum; SRB, sulforhodamin B; GI50, growth inhibition of $50 \%$

Key words: allium tuberosum L., thiosulfinates, apoptosis, primary human prostate cancer cells

\section{Introduction}

Prostate cancer is the most common male cancer in USA as well as other Western countries, and the second leading cause of male cancer death in the USA (1). Prostate cancer has become a more frequently diagnosed disease in Asian countries, potentially attributable to the Westernized dietary habits. There is no secure way to tell whether prostate cancer, once found, should receive treatment. There is no effective treatment modality once the cancer has evolved into the hormone refractory stage. Preventive strategies are currently emerging. There is an increase in the usage of nutritional supplements such as soybeans, garlic, green tea and vitamins D3 etc., to augment the prescribed anticancer therapies.

Allium tuberosum L., one of Allium spaces, contains thiosulfinates, and has been used as folk medicine as well as flavor foods. Allium tuberosum L. is also the major ingredient for leek Kimchi in Korea, which have long been used as a medicinal food for the treatment of abdominal pain, diarrhea, hematemesis, snakebite and asthma in folk remedies (2). Since the first detailed chemical report on thiosulfinates, many chemists and pharmacists have tried to separate and identify them by using GC-MS, LC-MS and NMR spectroscopy due to their striking biological activity $(3,4)$ and interesting organosulfur chemistry (5). Although GC and GC-MS analysis have provided excellent resolution and identification, many of the compounds from the Allium species observed by GC may have been artifacts of the analysis due to the high reactivity associated with the weak S-S bond (a bond energy $46 \mathrm{Kcal} \mathrm{mol}^{-1}$ or less) $(6,7)$. Several weaknesses also exist with the HPLC method such as retention time variation and the present limitation of LC-MS in characterizing volatile compounds (7). We reported first the separation of two thiosulfinates from Allium tuberosum $L$. by simple chromatography as previously described (8).

In the present study, we have evaluated the effect of thiosulfinates from Allium tuberosum L. on proliferation of metastasis and primary tumor-derived human prostate cancer cells. The induction of apoptosis and the mechanism of induced apoptosis of thiosulfinates were investigated. 


\section{Materials and methods}

Isolation of crude thiosulfinates. The thiosulfinates from Allium tuberosum L. were isolated using a previous method (8). The aerial parts of the plant were chopped and repeatedly extracted with $\mathrm{CH}_{2} \mathrm{Cl}_{2}(3 \times 4$ l) at room temperature. The extract was partitioned between $\mathrm{CH}_{2} \mathrm{Cl}_{2}$ and $5 \%$ aqueous lead acetate and then filtered. The filtrate was separated and the aqueous layer was re-extracted with $\mathrm{CH}_{2} \mathrm{Cl}_{2}$. The organic layer was washed with brine, dried over anhydrous $\mathrm{Na}_{2} \mathrm{SO}_{4}$, and then concentrated to give a thickish mass. This was then chromatographed in a silica gel column $(3.2 \times 38 \mathrm{~cm}, 230-400$ mesh) by eluting with a gradient of $\mathrm{CH}_{2} \mathrm{Cl}_{2}$-hexane [2:1 $(500 \mathrm{ml}), 4: 1(500 \mathrm{ml})$, and then 1:0 $(300 \mathrm{ml}) ; 20 \mathrm{ml}$ each]. The crude thiosulfinates, containing mostly S-methyl methanthiosulfinate and S-methyl 2-propene-1-thiosulfinate were isolated from Allium tuberosum L. using silica gel column chromatography (9).

Cell culture. Telomerase-immortalized primary human prostate cancer-derived cell line (RC-58T/h/SA\#4) (androgen positive cells) was derived from a 57 -year-old patient who had adenocarcinoma with poor differentiation (10). DU145 (androgen negative cells) cells were purchased from the Korea Cell Line Bank, Seoul National University. The cells were cultured in Dulbecco's modified Eagle's medium (DMEM) medium supplemented with $10 \%$ fetal bovine serum (FBS), penicillin $(100 \mathrm{IU} / \mathrm{ml})$, and streptomycin $(100 \mu \mathrm{g} / \mathrm{ml})(\mathrm{Gibco}-$ BRL, Life Technologies, Grand Island, NY) (DMEM + 10\% FBS) in a humidified atmosphere with a $5.5 \% \mathrm{CO}_{2}$ incubator, at $37^{\circ} \mathrm{C}$.

Cell proliferation assay. Cell proliferation was determined by using sulforhodamin B (SRB, Sigma, St. Louis, MO, USA) assay. The cells were seeded at a concentration of $5 \times 10^{4}$ cells/well in 48-well tissue culture plates and incubated with various concentration of thiosulfinates for various time period. After treatment, media were aspirated and $10 \%$ trichloro-acetic acid was added. After 1-h incubation at $4^{\circ} \mathrm{C}$, plate was washed 5 times by distilled water and air dried. Cells were stained with $0.4 \%(\mathrm{w} / \mathrm{v}) \mathrm{SRB}$ for $1 \mathrm{~h}$ at room temperature and washed 5 times by using $1 \%$ acetic acid. Bound SRB was solubilized with $10 \mathrm{mM}$ Tris and absorbance was measured at $540 \mathrm{~nm}$ (9). Cell number was also counted as another measure for cell growth. Briefly, after incubation with or without thiosulfinates, the cells were detached by $0.025 \%$ trypsin EDTA at $37^{\circ} \mathrm{C}$ for $2 \mathrm{~min}$ and then resuspended in PBS. The number of suspended cells was counted with a hemacytometer (11).

Cell cycle analysis and sub-G1 DNA measurement. The cells were seeded at a density of $1 \times 10^{6}$ cells in 6 -well plates, and cultured for $24 \mathrm{~h}$ in DMEM $+10 \%$ FBS. After culturing, the cells were treated with the indicated concentrations of thiosulfinates for $24 \mathrm{~h}$. For the growth inhibition analysis and measurement of sub-G1 DNA content, the cells were collected and fixed in ice-cold $70 \%$ ethanol in media and stored at $4^{\circ} \mathrm{C}$ overnight. After resuspension, the cells were washed and incubated with $1 \mu 1$ of RNase $(1 \mathrm{mg} / \mathrm{ml})$ (Sigma), $20 \mu 1$ of propidium iodide $(1 \mathrm{mg} / \mathrm{ml})$ (Sigma) and $500 \mathrm{ml}$ of
PBS at $37^{\circ} \mathrm{C}$ for $30 \mathrm{~min}$. After staining, flow cytometry was used to analyze the cell cycle phase and sub-G1 DNA content (12).

Detection of morphological apoptosis. Characteristic apoptotic morphological changes were assessed by fluorescent microscopy using bis-benzimide (Hoechst 332580) staining. Briefly, the cells were seeded in 6-well plates at seeding densities of $5 \times 10^{5}$ cells, and then treated with thiosulfinates $(0,5,10,15$ and $20 \mu \mathrm{g} / \mathrm{ml})$ for $24 \mathrm{~h}$. After harvesting, the cells were washed twice with PBS, and then stained with $200 \mu \mathrm{l}$ bis-benzimide $(1 \mu \mathrm{g} / \mathrm{ml})$ for $10 \mathrm{~min}$ at room temperature. Ten $\mu 1$ of this suspension was placed on a glass slide and covered with a cover slip. The cells were examined with a fluorescence microscope (Olympus Optical Co., Ltd., Japan) to determine nuclei fragmentation and chromatin condensation (13).

Analysis of DNA fragmentation. The Cell Death detection ELISA (Roche) was used to evaluate the presence of apoptosis activity in the cells after incubation with thiosulfinates for a period of $24 \mathrm{~h}$. After treatment, the cells were then lysed to release cytoplasmic histone associated DNA fragmentations, an indicator of apoptosis. Cell lysates were prepared and placed into streptavidin-coated microplates. These were incubated for $2 \mathrm{~h}$ at room temperature with anti-histonebiotin and anti-DNA-peroxidase antibodies. Calculation was done by measuring the absorbance at 405 against $490 \mathrm{~nm}$. Enrichment factor was calculated after normalization of protein amount in each treatment (14).

Assay for caspase activity. This assay was based on the ability of the active enzyme to cleave the chromophore from the enzyme substrate, Ac-DEVD-pNA (for caspase-3), Ac-IETD-pNA (for caspase-8), and Ac-LEHD-pNA (for caspase-9). The cells were seeded at a density of $2 \times 10^{6}$ cells in a $100-\mathrm{mm}$ dish, and cultured for $24 \mathrm{~h}$ in DMEM. After culturing, the cells were treated with the indicated concentrations of thiosulfinates for $24 \mathrm{~h}$, and then collected by centrifugation. The cells were incubated with the peptide substrate in lysis buffer for $30 \mathrm{~min}$ on ice, and centrifuged at $10,000 \mathrm{x} \mathrm{g}$ for $5 \mathrm{~min}$ at $4^{\circ} \mathrm{C}$. The protein content of the supernatant was measured using BCA protein assay reagent before analysis of the caspase- $3,-8$ and -9 activities. The supernatant that contained $50 \mu \mathrm{g}$ of protein was mixed with DTT in $2 \mathrm{X}$ reaction buffer and a $10 \mu \mathrm{M}$ concentration of the different substrates. After incubation, the release of p-nitroaniline was monitored at $405 \mathrm{~nm}$ (15).

Assay for caspase inhibitor activity. The cells were seeded at a density of $5 \times 10^{5}$ cells/well, and cultured for $24 \mathrm{~h}$ in DMEM $+10 \%$ FBS. The cells were preincubated with $\mathrm{z}-$ VAD-fmk for $2 \mathrm{~h}$, treated with the indicated concentrations of thiosulfinates for $24 \mathrm{~h}$. For the growth inhibition analysis and measurement of sub-G1 DNA content, the cells were collected and fixed in ice-cold $70 \%$ ethanol in media, and stored at $4^{\circ} \mathrm{C}$ overnight. After resuspension, the cells were washed and incubated with $1 \mu \mathrm{l}$ of RNase $(1 \mathrm{mg} / \mathrm{ml})$ (Sigma), $20 \mu 1$ of propidium iodide $(1 \mathrm{mg} / \mathrm{ml})$ (Sigma) and $500 \mathrm{ml}$ of $\mathrm{PBS}$ at $37^{\circ} \mathrm{C}$ for $30 \mathrm{~min}$. After staining, flow cytometry was 
used to analyze the cell cycle phase and sub-G1 DNA content (12).

Western blot analysis. The cells were seeded at a density of $2 \times 10^{6}$ cells in a $100-\mathrm{mm}$ dish, and cultured for $24 \mathrm{~h}$ in DMEM $+10 \%$ FBS. Then the cells were treated with the indicated concentrations of thiosulfinates for $24 \mathrm{~h}$, and collected by centrifugation. The pellets were lysed by lysis buffer $(50 \mathrm{mM}$ Tris- $\mathrm{HCl}, 150 \mathrm{mM} \mathrm{NaCl}, 1 \mathrm{mM}$ EDTA, $50 \mathrm{mM} \mathrm{NaF}, 30 \mathrm{mM} \mathrm{Na}{ }_{4} \mathrm{P}_{2} \mathrm{O}_{7}, 1 \mathrm{mM}$ PMSF and $2 \mu \mathrm{g} / \mathrm{ml}$ aprotinin) for $30 \mathrm{~min}$ on ice. The protein content of the supernatant was measured using BSA protein assay reagent before analysis. The protein samples were loaded at $10 \mu \mathrm{g}$ of protein/ lane and separated by SDS-PAGE in $12 \%$ gel at $100 \mathrm{~V}$ of constant voltage/slab for $1.5 \mathrm{~h}$. Following electrophoresis, the proteins were transferred onto nitrocellulose membranes. After blocking with 2.5 and $5 \%$ bovine serum albumin (BSA) for $1 \mathrm{~h}$ at $37^{\circ} \mathrm{C}$, the membranes were incubated with first antibody (anti-PARP, anti-Bid, anti-Bax, anti-Bcl2 and antiAIF) at $4^{\circ} \mathrm{C}$ overnight. Finally, the membranes were treated with horseradish peroxidase-coupled secondary antibodies for $1 \mathrm{~h}$ at $4^{\circ} \mathrm{C}$. The membranes were washed with T-TBS after each antibody binding reaction. Detection of each protein was performed using an ECL kit (16).

AIF translocation. The RC58T/h/SA\#4 cells were seeded in 6-well plates at seeding densities of $5 \times 10^{5}$ cells and then treated with thiosulfinates for $24 \mathrm{~h}$. After harvesting, the cells were washed twice with PBS and then blocked with blocking buffer (2\% BSA in T-TBS) for $1 \mathrm{~h}$. The cells were incubated with AIF primary antibody overnight at $4^{\circ} \mathrm{C}$, followed by anti-rabbit secondary antibody for $1 \mathrm{~h}$. AIF translocation was analyzed under a fluorescence microscope (Olympus Optical Co.) (17).

Statistical analysis. Data were analyzed by Student's t-test to evaluate significant differences. A level of $\mathrm{p}<0.05$ was regarded as statistically significant.

\section{Results}

Thiosulfinates inhibited cell growth of a primary human prostate cancer cell line. The RC-58T/h/SA\#4 cell line was derived from a soft agar clone of the RC-58T/h cell line, a telomerase-immortalized primary malignant tumor-derived human prostate epithelial cell line (10). To find the optional dose for thiosulfinate inhibition on prostate cancer cells, the cell growth of RC-58T/h/SA\#4 and DU-145 cells was determined in the presence of various doses of thiosulfinates following 24-h treatment. Cell viability decreased with increasing thiosulfinate concentrations and the GI50 values of thiosulfinates for $24-\mathrm{h}$ treatment were $4.58 \mu \mathrm{g} / \mathrm{ml}$ for $\mathrm{RC}-58 \mathrm{~T} / \mathrm{h} / \mathrm{SA \# 4}$ cells and $15.3 \mu \mathrm{g} / \mathrm{ml}$ for DU145 cells respectively (data not shown). In order to determine the timedependent inhibition of the thiosulfinates in prostate cancer cells, RC58T/h/SA\#4 and DU145 cells were treated with the various indicated concentrations of thiosulfinates and viability was assessed after 24,48 and $72 \mathrm{~h}$ of incubation. The anti-proliferation by the thiosulfinates in the RC58T/ h/SA\#4 and DU145 cells occurred in a treatment time-dependent
(A)

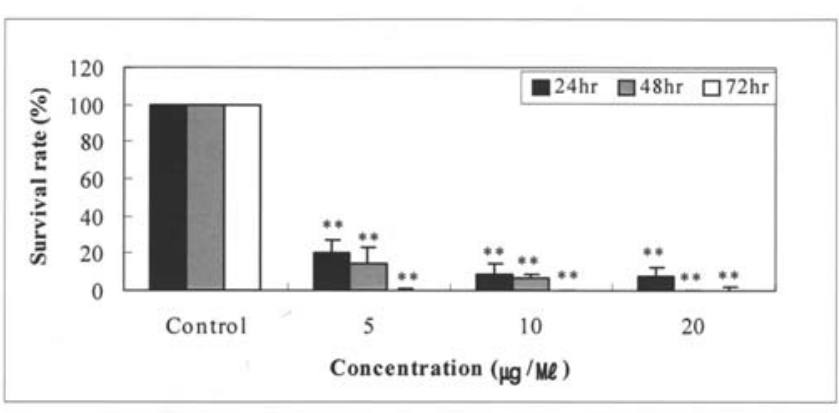

(B)

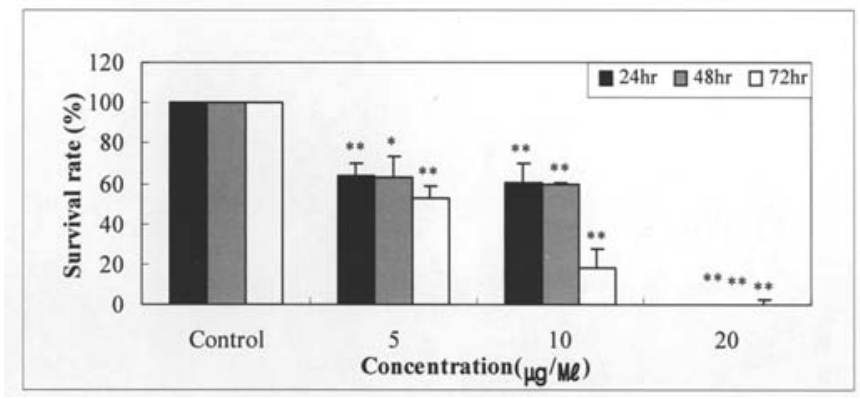

Figure 1. Cell growth inhibition of prostate cancer cells (RC58T/h/SA\#4, upper panel and DU145 cells, lower panel) treated with thiosulfinates for 24, 48 and $72 \mathrm{~h}$ determined by SRB assay. The cells were treated with thiosulfinates at $0-20 \mu \mathrm{g} / \mathrm{ml}$ for $72 \mathrm{~h}$, and then fixed and stained with SRB for cellular protein content analysis. Data values were expressed as mean $\pm \mathrm{SD}$ of triplicate determinations. Significant differences were compared with the control at ${ }^{*} \mathrm{p}<0.05$ and ${ }^{* *} \mathrm{p}<0.01$ by Student's t-tests.

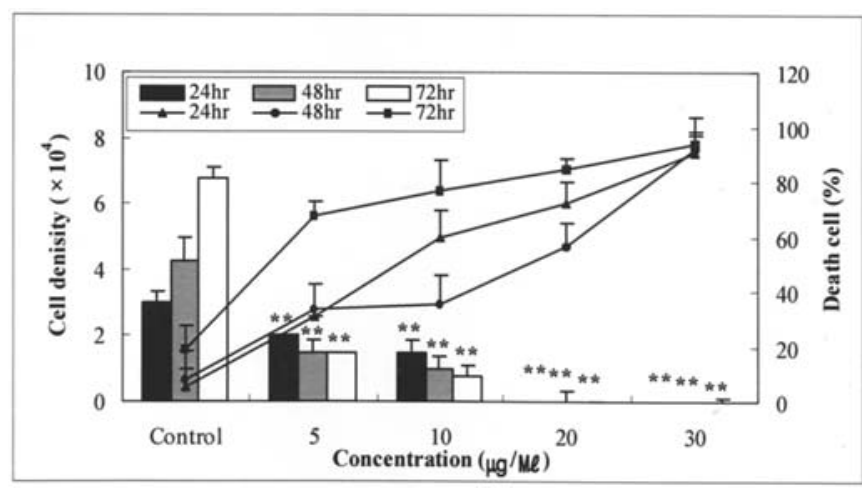

Figure 2. Cytotoxicities determined by cell count of the RC58T/h/SA\#4 cells treated with thiosulfinates for 24,48 and $72 \mathrm{~h}$. Results were expressed as the percentage of control. The bars and lines are means of the cell densities and cell deaths, respectively. The RC58T/h/SA\#4 cells were detached by trypsinization and harversted by resuspension in medium for immediate analysis of the cell number using a hemacytometer. Data values were expressed as mean \pm SD of triplicate determinations. Significant differences were compared with the control at " $\mathrm{p}<0.05$ and ${ }^{* *} \mathrm{p}<0.01$ by Student's t-test.

manner (Fig. 1). Also, as shown in Fig. 2, cell numbers decreased and cell death rates increased, in a dose-dependent manner, in the RC58T/h/SA\#4 cells treated with thiosulfinates. These results indicate that thiosulfinates inhibit the proliferation of prostate cancer cells in a concentration- and 


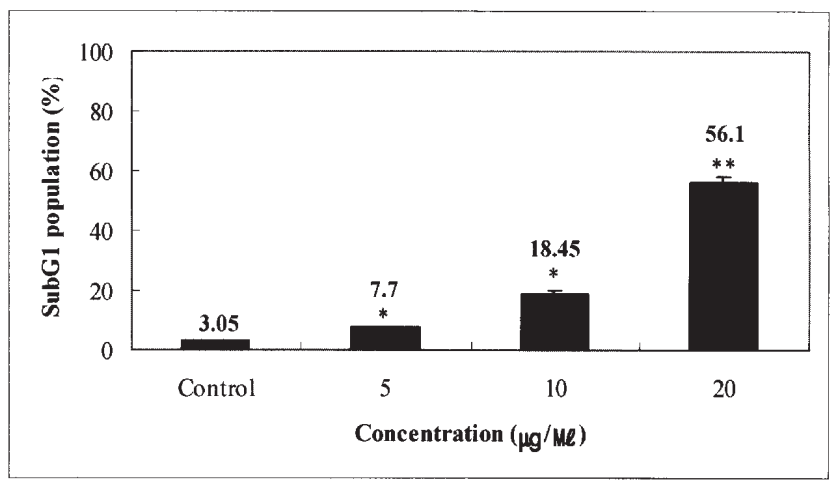

Figure 3. Sub-G1 population of RC58T/h/SA\#4 cells treated with thiosulfinates for $24 \mathrm{~h}$. The RC58T/h/SA\#4cells were cultured with different concentrations of thiosulfinates for $24 \mathrm{~h}$, fixed and stained with PI, and then DNA content was analyzed by flow cytometry. Data values were expressed as mean $\pm \mathrm{SD}$ of triplicate determinations. Significant differences were compared with the control at ${ }^{*} \mathrm{p}<0.05$ and ${ }^{* *} \mathrm{p}<0.01$ by Student's t-test.
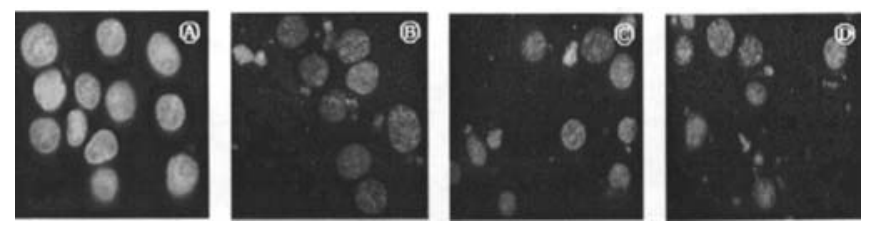

Figure 4. Nuclear fragmentation induced by thiosulfinates in RC58T/h/SA\#4 cells for $24 \mathrm{~h}$. (A) Non-treated. (B) RC58T/h/SA\#4 treated with $5 \mu \mathrm{g} / \mathrm{ml}$ of thiosulfinates. (C) RC58T/h/SA\#4 treated with $10 \mu \mathrm{g} / \mathrm{ml}$ of thiosulfinates. (D) RC58T/h/SA\#4 treated with $20 \mu \mathrm{g} / \mathrm{ml}$ of thiosulfinates. The cells were treated with thiosulfinates at $0-20 \mu \mathrm{g} / \mathrm{ml}$ for $24 \mathrm{~h}$, washed once with PBS and stained with $10 \mu \mathrm{l} / \mathrm{ml}$ of Hoechst 33258, and finally, examined under a fluorescence microscope.

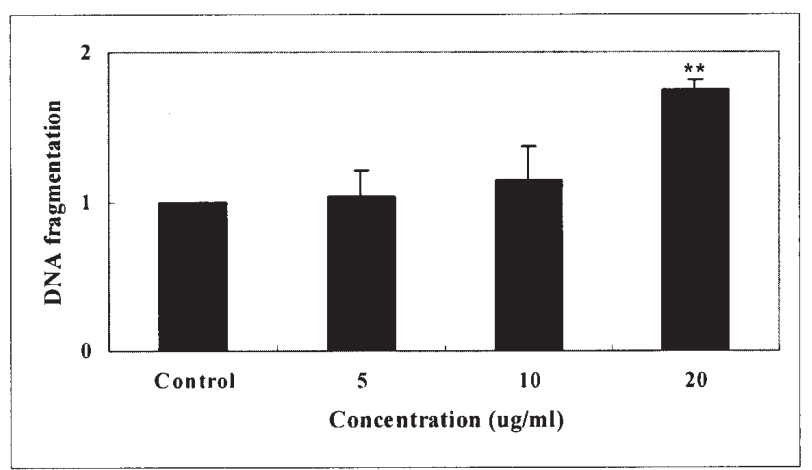

Figure 5. DNA fragmentation in RC58T/h/SA\#4 cell treated with thiosulfinates for $24 \mathrm{~h}$. The RC58T/h/SA\#4 cells were treated with thiosulfinates at $0-20 \mu \mathrm{g} / \mathrm{ml}$ for $24 \mathrm{~h}$, and then DNA fragmentation measured by ELISA kit. The DNA fragmentation activities were calculated by defining the activity of control as 1 . Data values were expressed as mean \pm SD of triplicate determinations. Significant differences were compared with the control at *** $\mathrm{p}<0.01$ by Student's t-test.

time-dependent manner, and their activities were stronger in $\mathrm{RC} 58 \mathrm{~T} / \mathrm{h} / \mathrm{SA \# 4}$ than in DU145 cells.

Cell cycle distributions and variation of sub-G1 by thiosulfinates. To assess the correlation between thiosulfinateinduced proliferation inhibition and cell cycle blockage, the effects of the thiosulfinates on cell cycle distribution were

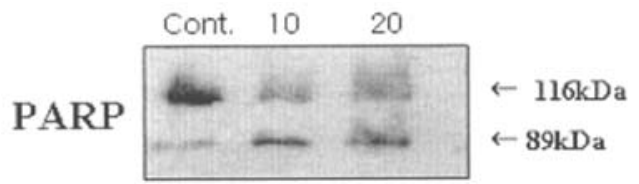

Figure 6. Apoptotic PARP cleaved fragmentation in RC58T/h/SA\#4 cells treated with thiosulfinates for $24 \mathrm{~h}$ by Western blot analysis.

(A)

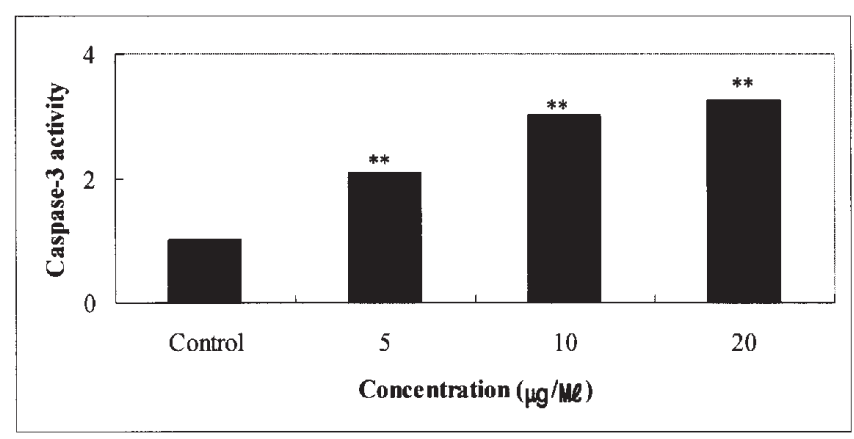

(B)

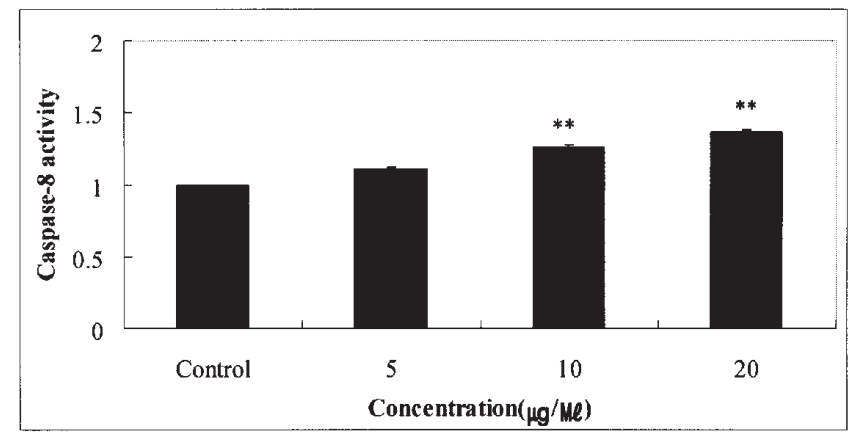

(C)

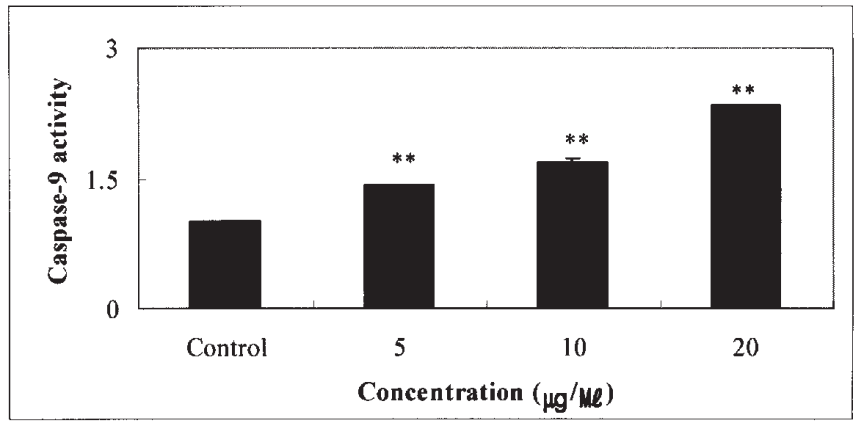

Figure 7. The effect of caspase activity in RC58T/h/SA\#4 cells treated with thiosulfinates. (A) Caspase-3 activity, (B) caspase-8 activity and (C) caspase- 9 activity. The caspase activities were calculated by defining the activity of control as 1 . Data values were expressed as mean $\pm \mathrm{SD}$ of triplicate determinations. Significant differences were compared with the control at "p $<0.05$ and $^{* *} \mathrm{p}<0.01$ by Student's t-test.

determined, and the results are summarized in Fig. 3. The proportion of the sub-G1 peak was negligible in the control $\mathrm{RC} 58 \mathrm{~T} / \mathrm{h} / \mathrm{SA} \# 4$ cells without thiosulfinates, whereas 24-h exposure of the RC58T/h/SA\#4 cells to 5,10 and $20 \mu \mathrm{g} / \mathrm{ml}$ of thiosulfinates resulted in cell accumulation at the sub-G1 phase in a dose-dependent manner. 


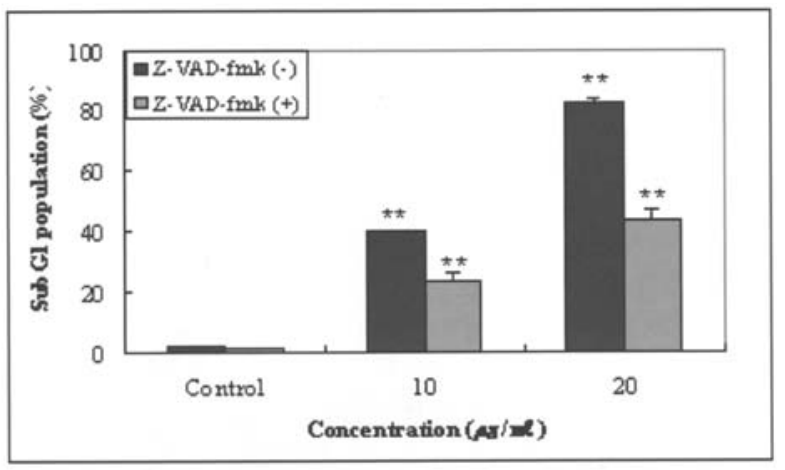

Figure 8. Effect of a caspase inhibitor (Z-VAD-fmk) on cell death induced by thiosulfinates. RC58T/h/SA\#4 cells were pre-incubated with $10 \mu \mathrm{M}$ of $\mathrm{Z}$-VAD-fmk for $2 \mathrm{~h}$ and then treated with various concentrations of thiosulfinates. Data values were expressed as mean \pm SD of triplicate determinations. Significant differences were compared with the control at ${ }^{* *} \mathrm{p}<0.01$ by Student's t-test.

Thiosulfinates induces programmed cell death. To assess whether or not the thiosulfinates induced apoptosis of the RC58T/h/SA\#4 cells, we performed Hoechst 33258 staining, DNA fragmentation by ELISA kit, and detection of PARP cleavage by Western blotting. After thiosulfinate treatment for $24 \mathrm{~h}$, most of RC58T/h/SA\#4 cells had shrunk and adhered together. Apoptotic bodies were also clearly observed in the thosulfinate-treated cells after staining with Hoechst 33258 (Fig. 4). Another distinct feature of apoptosis (DNA fragmentation activity), was seen in $\mathrm{RC} 58 \mathrm{~T} / \mathrm{h} / \mathrm{SA \# 4}$ cells after thiosulfinate treatment. The relative apoptotic levels in the cells treated with 5,10 and $20 \mu \mathrm{g} / \mathrm{ml}$ of thiosulfinates increased 1.03-, 1.13- and 1.73-fold from control cells, respectively (Fig. 5). For the cleavage of PARP, the antiPARP antibody recognized a $116-\mathrm{kDa}$ band, which corresponded to the intact PARP in the thiosulfinate treated- and untreated-RC58T/h/SA\#4 cells (Fig. 6). This 116-kDa band was intense in the control cells; however, it disappeared in the cells treated with thiosulfinate for 24-h incubation. In addition, the antibody also detected a band running at $\sim 89 \mathrm{kDa}$, which may correspond to the $89-\mathrm{kDa}$ fragmentation of PARP in the RC58T/h/SA\#4 cells after $48 \mathrm{~h}$ of treatment. This 89-kDa band was not seen in the untreated cells.

Caspase activation by thiosulfinates. Caspases, a family of cysteine proteases, are activated during the execution phase of an apoptotic process. Once activated, caspases activate downstream caspases, leading to apoptosis. The thiosul-

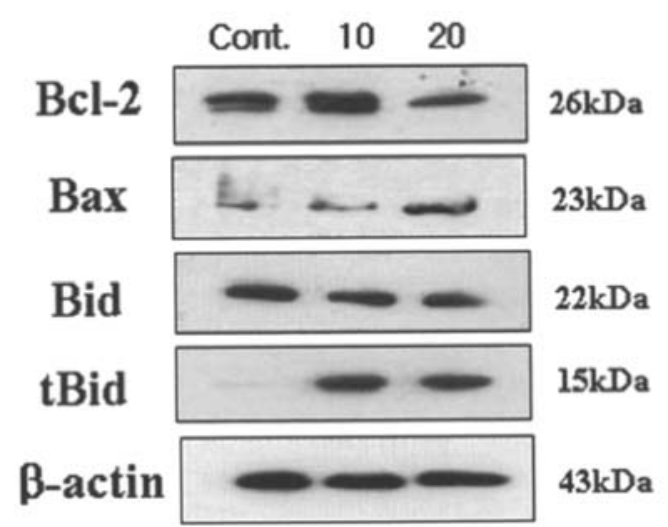

Figure 9. Thiosulfinates-induced apoptosis in the mitochondrial pathway. Expression level of Bcl-2 family protein in thiosulfinates treated RC58T/ $\mathrm{h} / \mathrm{SA \# 4}$ cells. Western blot analysis was assessed for protein expression. The cleaved Bid in thiosulfinate treated $\mathrm{RC} 58 \mathrm{~T} / \mathrm{h} / \mathrm{SA \# 4}$ cells. The cleavage of Bid was assessed by Western blotting.

finates significantly stimulated the activities of caspase-8, caspase- 9 , and caspase- 3 in the RC58T/h/SA\#4 cells by $1.3-$ 2.3- and 2.0 -fold at $20 \mu \mathrm{g} / \mathrm{ml}$ concentration, respectively (Fig. 7). To determine whether or not the apoptosis induced by thiosulfinates occurs via the caspase-dependent pathway, z-VAD-fmk, a universal caspase inhibitor, was added with the thiosulfinates. As shown in Fig. 8, although the caspase inhibitor reduced apoptosis by the thiosulfinates, cell death via the thiosulfinates was significantly elevated in a dosedependent manner.

The mitochondial apoptotic pathway involved in thiosulfinate-mediated apoptosis. To investigate the mitochondrial apoptotic events involved in thiosulfinate-induced apoptosis, we analyzed changes in the levels of pro-apoptotic protein Bax and anti-apoptotic protein Bcl-2 by Western blotting. As shown in Fig. 9 (upper panel), the thiosulfinates dosedependently increased expression of the pro-apoptotic protein Bax, but decreased expression of the anti-apoptotic protein $\mathrm{Bcl}-2$ in the $\mathrm{RC} 58 \mathrm{~T} / \mathrm{h} / \mathrm{SA} \# 4$ cells.

Since thiosulfinate-mediated apoptosis involved initiation of death receptor and mitochondrial signaling, it was possible that thiosulfinates activated the mitochondrial apoptotic pathway through caspase-8-mediated Bid cleavage, which then resulted in caspase- 9 activation. To test this idea, we checked the status of the Bid protein during thiosulfinateinduced apoptosis. Fig. 9 (middle panel) shows that a full
(A)

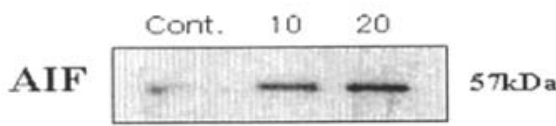

(B)

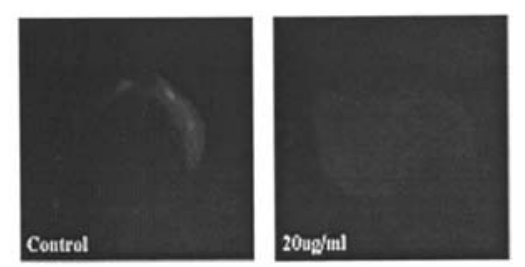

Figure 10. Thiosulfinate-induced apoptosis in the caspase-independent pathway. (A) The expression level of AIF protein in thiosulfinates from treated $\mathrm{RC} 58 \mathrm{~T} / \mathrm{h} / \mathrm{SA \# 4}$ cells for $24 \mathrm{~h}$. Western blot analysis was assessed protein expression. (B) Subcellular localization of AIF was analyzed by immunocytochemistry using an antibody against AIF. 
size Bid $(22 \mathrm{kDa})$ protein was cleaved to yield a $15-\mathrm{kDa}$ fragment following cell treatment with thiosulfinates, and this closely matched the appearance of capase- 8 activation.

AIF translocation. AIF is known to be involved in the induction of apoptotic cell death via a caspase-independent pathway. Mitochondrial AIF is released in response to death stimuli, and subsequently translocates into the nucleus, and causes nuclear condensation. We determined whether or not AIF played a role in thiosulfinate-induced apoptotic cell death by analyzing changes in the level of AIF by Western blotting (Fig. 10A), as well as AIF translocation into the nucleus by immunostaining (Fig. 10B). The results suggest that the thiosulfinates induced apoptosis via a caspaseindependent pathways in RC58T/h/SA\#4 cells.

\section{Discussion}

In the present study, we observed for the first time that thiosulfinates significantly inhibit cell growth of metastasisderived human prostate carcinoma (DU145) and primary tumor-derived human prostate cancer cells (telomeraseimmortalized RC-58T/SA/SA\#4 cells). The stronger inhibition was observed in the $\mathrm{RC}-58 \mathrm{~T} / \mathrm{h} / \mathrm{SA \# 4}$ cells. Cell numbers were decreased and cell death rates were increased in a dose- and time-dependent manners in the RC58T/h/SA\#4 cells treated with thiosulfinates. Since deregulation of cell proliferation and cell survival are major disorder in cancer cells (18), inhibiting cell proliferation and increasing apoptosis in tumors are effective strategies for preventing tumor growth (19).

Our results show also that thiosulfinates inhibited cell proliferation through apoptosis in $\mathrm{RC} 58 \mathrm{~T} / \mathrm{h} / \mathrm{SA \# 4}$ cells. Important features of apoptotic cell death are cell shrinkage, chromatin condensation, DNA fragmentation, and apoptotic bodies (20). We observed many apoptotic bodies in the $\mathrm{RC} 58 \mathrm{~T} / \mathrm{h} / \mathrm{SA \# 4}$ cells treated with 10 and $20 \mu \mathrm{g} / \mathrm{ml}$ of thiosulfinates for $24 \mathrm{~h}$. The thiosulfinate-treated RC58T/h/SA\#4 cells had accumulation of cells in the sub-G1 phase in a dosedependent manner, which is a common indication of the presence of apoptotic cells. Hoechst 33258 staining showed condensed nuclei and apoptotic bodies after exposure of the $\mathrm{RC} 58 \mathrm{~T} / \mathrm{h} / \mathrm{SA} \# 4$ cells to 10 and $20 \mu \mathrm{g} / \mathrm{ml}$ of thiosulfinates for $24 \mathrm{~h}$. Another distinct feature of apoptosis, a DNA fragmentation pattern, was seen in the RC58T/h/SA\#4 cells after thiosulfinate treatment. Interneucleosomal DNA fragmentation is a significant feature of apoptotic cell death, and this phenomenon is caused by caspase-activated DNAs and endonuclease $\mathrm{G}$, which cleave DNA between nucleosomes (21). The appearance of DNA fragmentation in the cells treated with thiosulfinates coincided with the occurrence of fragmented nuclei, as demonstrated by Hoechst staining.

PARP, a 116-kDa nuclear enzyme, seems to be involved in DNA repair by catalyzing the synthesis of PARP from nicotinamide adenine dinucleotide (22). Because PARP is important for cells to maintain their viability, the cleavage of PARP helps cellular disassembly, and serves as a marker of cells undergoing apoptosis (23). As the 116-kDa PARP band diminished, the intensity of $85-\mathrm{kDa}$ band linearly increased in the RC58T/h/SA\#4 cells that received $24 \mathrm{~h}$ of thiosulfinate treatment. PARP is one of the key cleavage targets of caspase-3 (24). We observed that thiosulfinates increased caspase-3 activity 3.0- and 3.2-fold at the $10 \mu \mathrm{g} / \mathrm{ml}$ and $20 \mu \mathrm{g} / \mathrm{ml}$, respectively. DNA fragmentation and nuclear chromatin condensation have been demonstrated in $\mathrm{RC} 58 \mathrm{~T} / \mathrm{h} / \mathrm{SA \# 4}$ cells by thiosulfinates. Moreover, the observations of caspase- 3 activation and PARP cleavage also confirm that the promotion of apoptosis by thiosulfinates involves a caspase-dependent pathway.

To elucidate the apoptotic mechanism induced by thiosulfinates in RC-58T/h/SA\#4 cells, we evaluated their effects on caspase- 8 and caspase- 9 activities. The results showed that caspase- 8 and caspase- 9 activities significantly increased in the RC58T/h/SA\#4 cells after $24 \mathrm{~h}$ of incubation with thiosulfinates. Activation of the caspase cascade is a key element in the apoptotic process. Caspase- 8 and -9 are involved in the death receptor pathway and mitochondrial pathway, respectively. However, caspase- 8 can activate caspase- 9 through the proteolysis of Bid, a member of the Bcl-2 family (25). We have observed that thiosulfinates enhanced Bid cleavage in the RC58T/h/SA\#4 cells. Thus, the induction of apoptosis by the thiosulfinates might have been mediated through the death receptor pathway. Furthermore, although the inhibition of cell growth by the thiosulfinates decreased in the $\mathrm{RC} 58 \mathrm{~T} / \mathrm{h} / \mathrm{SA \# 4}$ cells treated with the caspase family inhibitor, cell death was significantly elevated in a dosedependent manner. This result suggests that thiosulfinates might induce apoptosis via both caspase-dependent and -independent pathways (Fig. 8). We have found that the thiosulfinates increased the expression of the pro-apoptotic protein Bax and decreased the expression of anti-apoptotic $\mathrm{Bcl}-2$ in the $\mathrm{RC} 58 \mathrm{~T} / \mathrm{h} / \mathrm{SA} \# 4$ cells, and then activated caspase-9, which in turn activated caspase- 3 . These findings suggest that apoptosis induction in thiosulfinate-treated $\mathrm{RC} 58 \mathrm{~T} / \mathrm{h} / \mathrm{SA} \# 4$ cells could be associated with a caspasedependent cascade that involves the activation of the mitochondrial pathway, initiated by the inhibition of $\mathrm{Bcl}-2$ and activation of Bax.

On the other hand, the thiosulfinates elevated AIF protein expression and AIF translocation into the nucleus. AIF is a mitochondrial apoptosis-inducing factor implicated in apoptosis, and a mitochondrial flavoprotein that translocates to the nucleus following apoptotic stimuli. In the nucleus, AIF induces partial DNA fragmentation and chromatin condensation. AIF appears to promote apoptosis independent of caspase, although it likely acts in a cooperative manner with other factors to promote nuclear apoptosis.

In conclusion, we demonstrated that thiosulfinates from Allium tuberosum L. exert RC58T/h/SA\#4 human prostate cancer cell growth inhibition by the induction of apoptosis. Apoptotic mechanisms of thiosulfinates may be mediated by caspase-independent as well as caspase-dependent pathways in the cells.

\section{Acknowledgments}

This work was supported by the Korea Research Foundation Grant funded by the Korean Government (MOEHRD) (KRF-2004-042-F00028). 


\section{References}

1. Nishimura $\mathrm{H}$, Takahashi T, Wijaya $\mathrm{CH}$, Satoh A and Ariga T: Thermochemical transformation of sulfur compounds in Japanese domestic Allium victorialis L. BioFactors 13: 257-263, 2000.

2. Wanger H, Dorsh W, Bayer T, Breu W and Willer F: Antiasthmatic effects of onions: Inhibition of 5-lipoxigenase and cyclooxygenase in vitro by thiosulfinates and 'cepaenes'. Prostaglandins Leukotrienes Essen Fatty Acids 39: 59-62, 1990.

3. Sendl A, Schliack M, Loser R, Stanislaus F and Wanger H: Inhibition of cholesterol synthesis in vitro by extracts and isolated compounds prepared from garlic and wild garlic. Atherosclerosis 94: 79-95, 1992.

4. Block E and O'Connor J: The chemistry of alkyl thiolsulfinate esters. VII. Preparation and spectral studies. J Am Chem Soc 96: 3921-3929, 1974.

5. Bernhard R: Chemotaxnomy: distribution studies of sulfur compounds in Allium. Phytochemistry 9: 2019-2027, 1970.

6. Block E and O'Connor J: The chemistry of alkyl thiolsulfinate esters. VII. Mechanistic studies and synthetic application. J Am Chem Soc 96: 3929-3944, 1974.

7. Block E, Putman D and Zhao S-H: Allium chemistry: GC-MS analysis of thiosulfinates and related compounds from onion, leek, scallion, shallot, chive and Chinese chive. J Agric Food Chem 40: 2431-2438, 1992.

8. Seo KI, Moon YH, Choi SU and Park KH: Antibacterial activity of S-metyl methanethiosulfinate and S-methyl 2-propene-1thiosulfinate from Chinese chive toward Escherichia coli O157: H7. Biosci Biotechnol Biochem 65: 966-968, 2001.

9. Moon SO, Lee JH and Kim TJ: Changes in the express of c-myc, RB and tyrosine-phosphorylated proteins during proliferation of NIH 3 T3 cells induced by hyaluronic acid. Exp Mol 30: 29-33, 1998

10. Gu YP, Li HZ, Miki J, Kim KH, Furusato BG, Sesterhenn IA, Chu WS, McLeod DG, Srivastava S, Ewing CM, Isaacs WB and Rhim JS: Phenotypic characterization of telomeraseimmortalized primary non-malignant and malignant tumorderived human prostate epithelial cell lines. Cancer Res 312: 831-843, 2006.

11. Wnag W, Heedeman L, Chung CS, Pelling JC, Koehler KJ and Birt DF: Cell-cycle arrest at $\mathrm{G} 2 / \mathrm{M}$ and growth inhibition by apigenin in human colon carcinoma cell lines. Mol Carcinog 28: 102-110, 2000

12. Park SY, Cho SJ, Kwon HC, Lee KR, Rhee DK and Pyo S: Caspase-independent cell death by allicin in human epithelial carcinoma cells: involvement of PKA. Cancer Lett 224: 123-132, 2005 .
13. Ricote M, García-Tuñón I, Fraile B, Fernández C, Aller P, Paniagua R and Royuela M: P38 MAPK protects against TNF- $\alpha$-provoked apoptosis in LNCaP cancer cells. Apoptosis 11: 1969-1975, 2006.

14. Yu Z and Li WJ: Induction of apoptosis by puerain in colon cancer HT-29 cells. Cancer Lett 238: 53-60, 2006.

15. Kuo PL, Hsu YL, Chang CH and Lin CC: The mechanism of ellipticine-induced apoptosis and cell cycle arrest in human breast MCF-7 cancer cells. Cancer Lett 223: 293-301, 2005.

16. Wan CK, Wang C, Cheung HY, Yang MS and Fong WF: Triptolide induces Bcl-2 cleavage and mitochondria dependent apoptosis in p53-dependent HL-60 cells. Cancer Lett 241: 1-11, 2005.

17. Kang YH, Yi MJ, Kim MJ, Park MT, Bae SW, Kang CM, Cho CK, Park IC, Park MJ, Rhee CH, Chung HY, Lee YS and Lee SJ: Caspase-independent cell death by arsenic trioxide in human cervical cancer cells: reactive oxygen species mediated poly(ADP-ribose) polymerase-1 activation signals apoptosisinducing factor release from mitochondria. Cancer Res 64: 8960-8967, 2004.

18. Evan GI and Vousden KH: Proliferation, cell cycle and apoptosis in cancer. Nature 6835: 342-348, 2001.

19. Kim EJ, Lee YJ, Shin HK and Park Yoon JH: Induction of apoptosis by the aqueous of Rubus coreanum in HT-29 human colon cancer cells. Nutrition 21: 1141-1148, 2005.

20. Saraste A and Pulkki K: Morphologic and biochemical hallmarks of apoptosis. Cardiovasc Res 45: 528-537, 2000

21. Nagata S: Apoptotic DNA fragmentation. Exp Cell Res 256: $12-18,2000$

22. Satoh MS and Lindahl T: Role of poly(ADP-ribose) formation in DNA repair. Nature 356: 356-358, 1992.

23. Oliver FJ, De la Rubia G, Rolli V, Ruiz-Ruiz MC, De Murcia G and Murcia JM: Importance of poly(ADP-ribose) polymerase and its cleavage in apoptosis. Lesson from an uncleavable mutant. J Biol Chem 273: 33533-33539, 1998.

24. Nicholson DW, Ali A, Thormberry NA, Vaillancourt JP, Ding CK, Gallant M, Gareau Y, Griffin PR, Labelle M, Lazebnik YA, Munday NA, Raju SM, Smulson ME, Yamin TT, Yu V and Miller DK: Identification and inhibition of the ICE/ CED-3 protease necessary for mammalian apoptosis. Nature 376: 37-43, 1995.

25. Li H, Zhu H, Xu CJ and Yuan J: Cleavage of Bid by caspase-8 mediated mitochondrial damage in the Fas pathway of apoptosis. Cell 94: 491-501, 1998. 